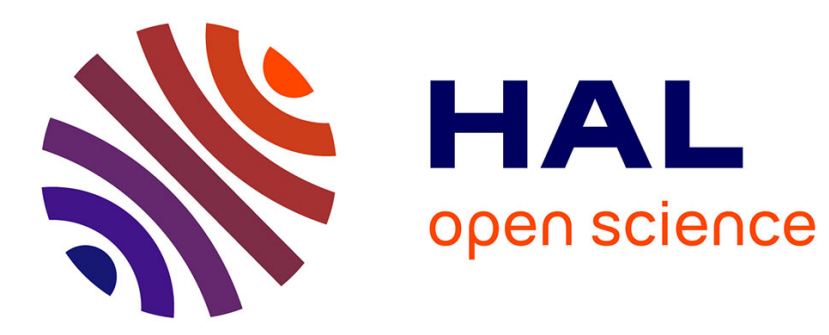

\title{
Boron doped graphene synthesis using pulsed laser deposition and its electrochemical characterization
}

Yannick Bleu, Florent Bourquard, Carole Farre, Carole Chaix, Jules Galipaud, Anne-Sophie Loir, Vincent Barnier, Florence Garrelie, Christophe Donnet

\section{- To cite this version:}

Yannick Bleu, Florent Bourquard, Carole Farre, Carole Chaix, Jules Galipaud, et al.. Boron doped graphene synthesis using pulsed laser deposition and its electrochemical characterization. Diamond and Related Materials, 2021, 115, pp.108382. 10.1016/j.diamond.2021.108382 . hal-03187937

\section{HAL Id: hal-03187937 \\ https://hal.science/hal-03187937}

Submitted on 18 Oct 2021

HAL is a multi-disciplinary open access archive for the deposit and dissemination of scientific research documents, whether they are published or not. The documents may come from teaching and research institutions in France or abroad, or from public or private research centers.
L'archive ouverte pluridisciplinaire HAL, est destinée au dépôt et à la diffusion de documents scientifiques de niveau recherche, publiés ou non, émanant des établissements d'enseignement et de recherche français ou étrangers, des laboratoires publics ou privés. 


\title{
Boron doped graphene synthesis using pulsed laser deposition and its electrochemical characterization
}

Yannick Bleu ${ }^{1}$, Florent Bourquard ${ }^{1}$, Carole Farre ${ }^{2}$, Carole Chaix ${ }^{2}$, Jules Galipaud ${ }^{3}$, Anne-Sophie Loir ${ }^{1}$, Vincent Barnier $^{4}$, Florence Garrelie ${ }^{1}$, and Christophe Donnet ${ }^{1}$

\footnotetext{
(1) Université de Lyon, Université Jean Monnet-Saint-Etienne, CNRS, Institut d'Optique Graduate School, Laboratoire Hubert Curien UMR 5516, F-42023, SAINT-ETIENNE, France

(2) Université de Lyon, Institut des Sciences Analytiques, UMR 5280 CNRS, Université Claude Bernard Lyon 1, F-69100 Villeurbanne, France

(3) Université de Lyon, LTDS, UMR CNRS 5513, Ecole Centrale de Lyon, 36 Avenue Guy de Collongue, F69134 Ecully Cedex, France

(4) Université de Lyon, Mines Saint-Etienne, CNRS, Laboratoire Georges Friedel UMR 5307 CNRS, F-42023 SaintEtienne, France
}

\begin{abstract}
During the design of graphene materials, their electronic, chemical and electrochemical properties -among others- can be tuned by incorporating heteroatoms in the honeycomb structure. In this study, we investigated boron doped graphene synthesis and the effect of boron content on the electrochemical property of graphene. To this end, boron-doped graphene (BG) was synthesized using pulsed laser deposition (PLD) with carbon and boron as solid sources, followed by rapid thermal annealing (RTA) in the presence of a nickel based thin film catalyst at a growth temperature of $900^{\circ} \mathrm{C}$. The $\mathrm{BG}$ samples were characterized using standard spectroscopic techniques. Raman spectroscopy revealed that the as-prepared BG films consisted of few-layer graphene. Boron doping increased the level of defects in the films and also affected the formation of the graphene layer. X-ray photoelectron spectroscopy (XPS) demonstrated that boron atoms can be successfully doped into the graphene structure with control of boron content of around 1 and 2.5 at.\%. Electrochemical characterization of undoped graphene $(\mathrm{G})$ and boron-doped graphene $(\mathrm{BG})$ was also performed by cyclic voltammetry using redox ferrocene dimethanol. BG electrodes exhibited higher reversibility than the G electrode. Moreover, the heterogeneous electron transfer constant of the BG electrode with higher boron content of 2.5 at.\% was twice that of the G electrodes. This indicates that BG electrodes have better electrochemical properties with respect to the $\mathrm{G}$ electrode. All these results prove that the pulsed laser deposition method is a viable alternative way to produce BG films with excellent electrochemical properties.
\end{abstract}




\section{Introduction}

Incorporating dopants in the graphene structure with various heteroatoms can be used to modulate the bandgap and tune the electronic, physical-chemical and optical properties of graphene for many applications in electrochemistry, sensors, photovoltaics and catalysis. In the recent past, Wang et al.[1] reviewed graphene doping with different heteroatom elements including boron, nitrogen, phosphorus, group $\mathrm{VIa}(\mathrm{O}, \mathrm{S})$ and group $\mathrm{VIIa}(\mathrm{F}, \mathrm{Cl}, \mathrm{Br}, \mathrm{I})$ elements. More recently, Agnoli et al. [2] reviewed boron-doped graphene (BG) films, and pointed to both theoretical and experimental studies on structure and properties, as well as methods for synthesis, and potential applications in many areas. Indeed, the incorporation of boron in the structure of graphene, which has been less frequently investigated than nitrogen doping, increases the concentration of holes, inducing a p-doping effect, with a downshift of the Fermi level toward the Dirac point [3]. As boron atoms cause $\mathrm{sp}^{2}$ hybridization in the carbon lattice, the planar structure of graphene is preserved. Likewise, lower strain energy is generated in the graphene network by substitutional boron doping because B-C bonds in graphene are slightly longer than C-C bonds. Due to the strong B-C bond energy, the mechanical properties of graphene are preserved but the thermal conductivity of boron-doped graphene (BG) is drastically reduced compared to pristine graphene[2]. Furthermore, the B-C bond introduces defects in the nearby sites because a boron atom possesses three valence electrons leading to uneven charge distribution, which can facilitate charge transfer between neighboring carbon atoms and therefore enhance their electrochemical performance[4]. Many routes for the production of boron-doped graphene (BG) films have been investigated including liquid state synthesis [5-8], chemical vapor deposition (CVD) synthesis [9-16], and solid-phase synthesis [17-27]. CVD has been widely and successfully used for high-quality graphene synthesis over large areas, and using different sources of boron to produce BG films but they all usually require high-temperature treatment and metal boride compounds can form on the catalytic substrate [913]. Moreover, controlling the concentration of boron in CVD synthesized BG films is not simple. Solid-state synthesis using a solid carbon source, e.g. using the PLD method, has been shown to be capable of producing both pristine and doped graphene [28-30]. In our most recent work [31], we demonstrated the use of this alternative route for the first time: it consists of using carbon and boron solid precursors_ablated by pulsed laser in controlled conditions, to synthesize BG films. We also already demonstrated the ability of PLD to produce boron-doped diamond-like carbon films (a-C:B)[32], thereby providing a considerable baseline for advances in the synthesis of boron-doped graphene (BG) films. In the present work, we addressed the 
relationship between the chemical composition and nanostructure of BG films produced using PLD with their electrochemistry properties. To this end, after BG film synthesis using PLD and RTA, the as-grown samples were characterized using XPS, Raman, and cyclic voltammetry for chemical, structural, and electrochemical analysis.

\section{Experimental details}

B-Graphene growth. This stage involves three main steps: the deposition of nickel thin film catalyst by thermal evaporation, the deposition of a-C:B film on the cleaned $\mathrm{SiO}_{2}(300 \mathrm{~nm}) / \mathrm{Si}$ substrates using pulsed laser deposition (PLD), and the thermal annealing process responsible for the diffusion-segregation of carbon through nickel.

Firstly, after being cleaned ultrasonically in acetone, ethanol, and deionized water baths, the $\mathrm{SiO}_{2}(300 \mathrm{~nm}) / \mathrm{Si}$ substrate was placed in a vacuum chamber pumped to a base pressure of $10^{-6}$ mbar. Next, a 50-nm thick nickel (Ni) film was deposited by thermal evaporation on the top of the $\mathrm{SiO}_{2}(300 \mathrm{~nm}) / \mathrm{Si}$ substrate. Secondly, the $\mathrm{Ni}(50 \mathrm{~nm}) / \mathrm{SiO}_{2}(300 \mathrm{~nm}) / \mathrm{Si}$ was placed in the vacuum PLD chamber and pumped to a base pressure of $10^{-7}$ mbar. The co-ablation was operated at room temperature by an excimer laser $\mathrm{KrF}$ with $248 \mathrm{~nm}$ wavelength, a pulse duration of $20 \mathrm{~ns}$, a repetition rate of $10 \mathrm{~Hz}$ an energy per pulse of $160 \mathrm{~mJ}$. The energy density (fluence) of the laser beam was kept constant at $6.2 \mathrm{~J} / \mathrm{cm}^{2}$. In these conditions, the ablation rates of the carbon (99.997\%) and boron (99, $993 \%$ ) were respectively $26 \mathrm{~nm} \cdot \mathrm{mn}^{-1}$ and $1 \mathrm{~nm} \cdot \mathrm{mn}^{-1}$. The sequences of co-ablation were defined to deposit an a-C:B film $4 \mathrm{~nm}$ thick, with a boron concentration of 9 and 4.5 at.\%. A pure a-C film of similar thickness was also deposited on $\mathrm{Ni}(50 \mathrm{~nm}) / \mathrm{SiO}_{2}(300 \mathrm{~nm}) / \mathrm{Si}$ for the purpose of comparison. Thirdly, thermal annealing of the a$\mathrm{C}: \mathrm{B} / \mathrm{Ni} / \mathrm{SiO}_{2}(300 \mathrm{~nm}) / \mathrm{Si}$ film was performed at $900{ }^{\circ} \mathrm{C}$ for $7 \mathrm{~min}$ at a pressure of $10^{-2} \mathrm{mbar}$ in a rapid thermal annealing (RTA) oven with a heating ramp of $15^{\circ} \mathrm{C} / \mathrm{s}$ and a cooling ramp of about $0.5^{\circ} \mathrm{C} / \mathrm{s}$, to obtain graphene and boron-doped graphene on the top surface.

Characterization. The as-grown samples were analyzed using Raman spectroscopy to identify the graphene structure and XPS to analyze chemical composition and bonding. Raman spectroscopy was performed using an Aramis Jobin Yvon spectrometer at $442 \mathrm{~nm}(2.81 \mathrm{eV})$, with a spectral resolution of $2 \mathrm{~cm}^{-1}$ and a lateral resolution of $\sim 1 \mu \mathrm{m}$. The laser beam was focused on the sample with a $\times 100$ objective and the laser power was kept below $3 \mathrm{~mW}$ to avoid damaging the surface of the film. Raman components were associated with a Lorentzian fit, except for the asymmetric G peak, which was fitted using a Breit-Wigner- Fano function. A custom fitting function was computed for all recorded spectra, and a simple linear function was 
added to eliminate the background. This enabled access to the exact values of the various peak positions, widths, and maximum peak height intensities. Raman maps were built from the acquisition of each $1 \mu \mathrm{m}$ spectrum over probed surfaces measuring $20 \times 20 \mu \mathrm{m}^{2}$. The XPS measurement was carried out using a ULVAC-PHI Versaprobe II spectrometer with a focused monochromatic AlKa source $(\mathrm{h} v=1,486.68 \mathrm{eV}, 200 \mu \mathrm{m}$ spot size). For all the samples analyzed, narrow scans were recorded for C1s, B1s, and O1s with a step size of $0.1 \mathrm{eV}$ and 23 eV pass energy. The data were processed using Casa XPS, and Origin software. The binding energy of all the samples was calibrated using the reference C1 binding energy (284.8 $\mathrm{eV})[33,34]$. Quantification was carried out using the transmission function of the apparatus and angular distribution correction for an angle of $45^{\circ}$. Sensitivity factors were extracted from the work of Wagner et. al. [35] in which the cross section and escape depth correction are incorporated. The electrochemistry performance of these samples was recently examined using cyclic voltammetry curves.

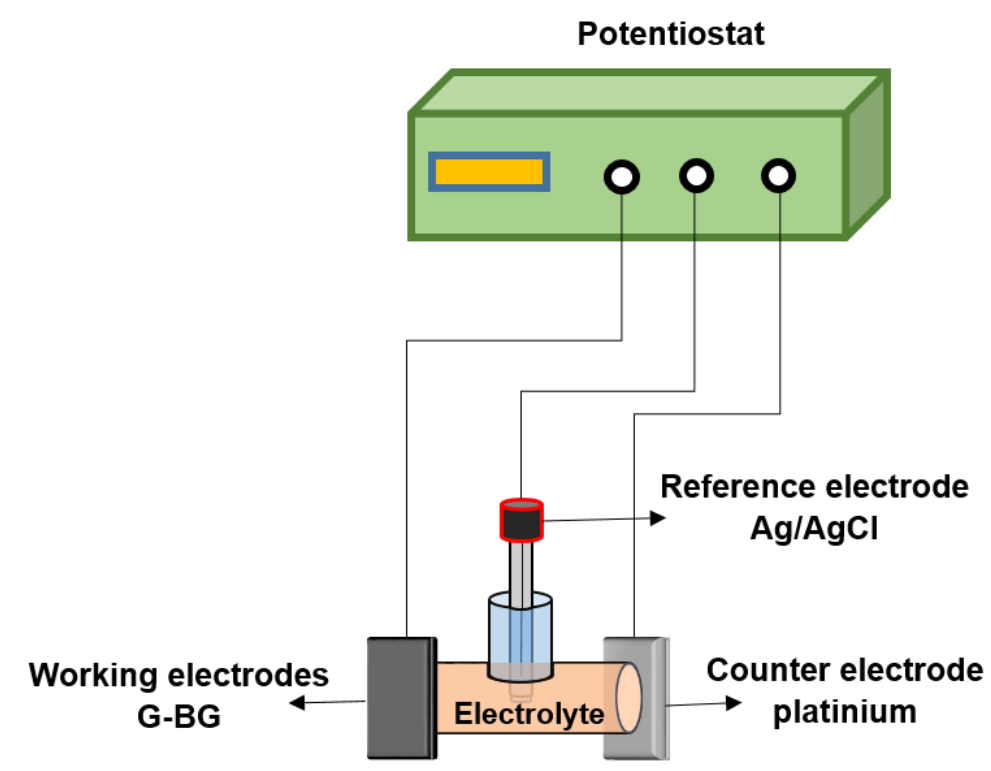

Figure 1. Schematic of the set up of our three electrodes system: the working electrodes are G and BG, the counter electrode is platinum, the reference electrode is $\mathrm{Ag} / \mathrm{AgCl}$, and the electrolyte is $0.5 \mathrm{mM} 1,1$ ferrocene-dimethanol solution of $0.1 \mathrm{M} \mathrm{NaClO}_{4}$.

Electrochemical measurements were carried out using a conventional three-electrode system with an internal volume of $5 \mathrm{~mL}$ at room temperature (Figure 1). This electrochemical cell was designed to maintain a fixed distance between the electrodes. This feature prevented further manipulation or movement of the electrodes (thereby fixing the cell geometry and insuring the reproducibility of the measurements). $\mathrm{An} \mathrm{Ag} / \mathrm{AgCl}$ was used as the reference electrode ($0.014 \mathrm{~V}$ versus SCE), a planar platinum electrode $\left(0.59 \mathrm{~cm}^{2}\right)$ was used as the counter electrode 
and the undoped graphene and boron-doped graphene samples were the working electrodes. This three-electrode system was connected to a Bio-Logic potentiostat. The results were recorded using EC-Lab software (v11.27) (Bio-Logic Science Instruments). To characterize the electron transfer rate for the different undoped and boron-doped graphene samples, cyclic voltammetry was performed three times in a $0.5 \mathrm{mM} 1,1$ ferrocene-dimethanol solution of $0.1 \mathrm{M}$ $\mathrm{NaClO}_{4}$ with a potential ranging between -0.2 and $0.6 \mathrm{~V}$ vs $\mathrm{Ag} / \mathrm{AgCl}$ at a scan rate of $50 \mathrm{mV}$ $\mathrm{s}^{-1}$. Only the last cycles were used to interpret the data.

\section{Results and discussion}

\subsection{Structural and chemical analysis of the synthesized films}

We investigated the nanostructure and chemical composition of the synthesized graphene and boron-doped graphene using Raman spectroscopy and XPS. Particular attention was paid to the difference between the features of the undoped and boron-doped graphene films, as well to the boron content in both a-C:B precursors and BG films. For this reason, prior to BG films, in this section, we included detailed XPS analysis of the a-C:B precursors. We observed the presence of carbon, boron, and oxygen in the survey spectra (data not shown) of the a-C:B films. The nickel was probably not detected because the top surface a-C:B film masks its contribution. On the contrary, in the survey spectra of the BG films, we observed not only C1s, B1s, and O1s, but also Ni2p, Si2s and Si2p. This is consistent with the well-known growth mechanism of graphene from a solid carbon-based precursor in the presence of a metal catalyst $[36,37]$ : the constituents of the solid carbon film diffuse into the catalyst and segregate as graphene layers on the top surface of the catalyst during the annealing and cooling process. Moreover, annealing at $900^{\circ} \mathrm{C}$ causes dewetting of the $\mathrm{Ni}$ film, which leads to the concomitant formation of $\mathrm{Ni}$ nodules and of the graphene layer [38-41]. Those considerations may explain why $\mathrm{Ni}$ and $\mathrm{Si}$ were detected by XPS. Further, the presence of oxygen in the a-C:B precursor sample can be attributed to adventitious contamination and oxygen incorporation in the films due to residual water vapor in the PLD chamber (maintained at around $10^{-7}$ mbar during deposition) or during storage in the air after deposition. After rapid thermal annealing, we observed that the a-C:B of 4.5 at.\% of boron produces BG film containing 1 at.\% of boron, and the a-C:B precursor of 9 at.\% of boron produces BG film with 2.5 at.\%. Note that these percentages are related to the ratio $\mathrm{B} /(\mathrm{B}+\mathrm{C})$. When we compared the boron content of the $\mathrm{BG}$ films with their precursors, we therefore observed a systematic loss of boron after the annealing process, at both boron concentrations. This could be attributed to the thermal annealing process, which may provoke 
cause the diffusion of boron atoms in the nickel catalyst during the synthesis of BG films, via a mechanism that remains to be clarified.

Using high-resolution core-level spectra, we performed peak deconvolution to reveal the detailed configurations of the boron, carbon, and oxygen. Moreover, the peak deconvolutions and their exact interpretation are rather controversial due to the proximity of electronic configurations of carbon and boron with a slight difference in their electronegativity, as well as to the existence of numerous chemical functions combining $\mathrm{B}, \mathrm{C}$ and $\mathrm{O}$ species. Our interpretation of XPS is based on a compilation of previously published data related to borondoped graphene [21,42-47]. The XPS spectra depicted in Figure 2a-c show the B1, C1, and O1 core levels of the a-C:B film containing 9 at.\% of boron, as deposited by the co-ablation process of carbon and boron (i.e. before annealing allows its conversion into boron-doped graphene).

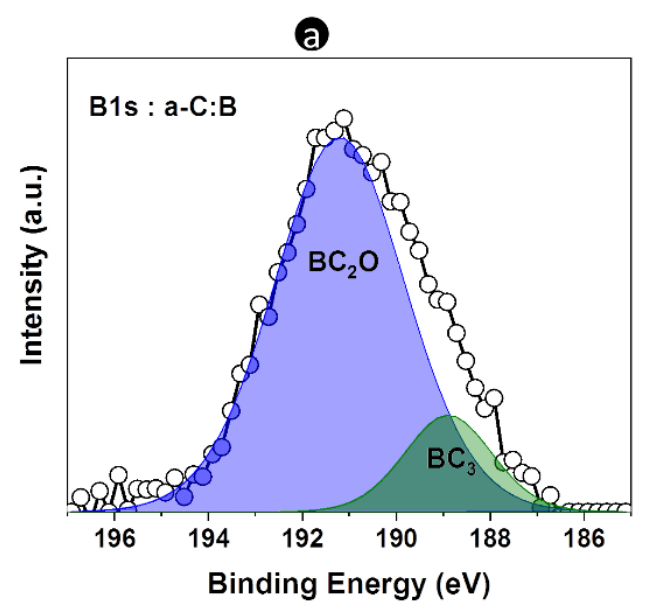

(b

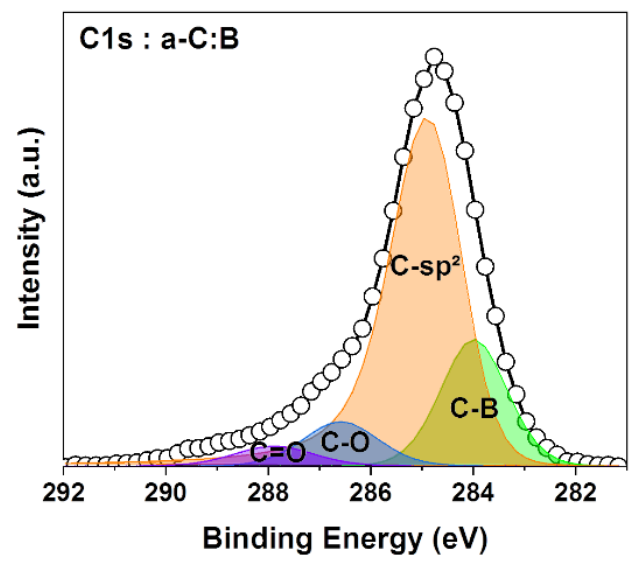

c

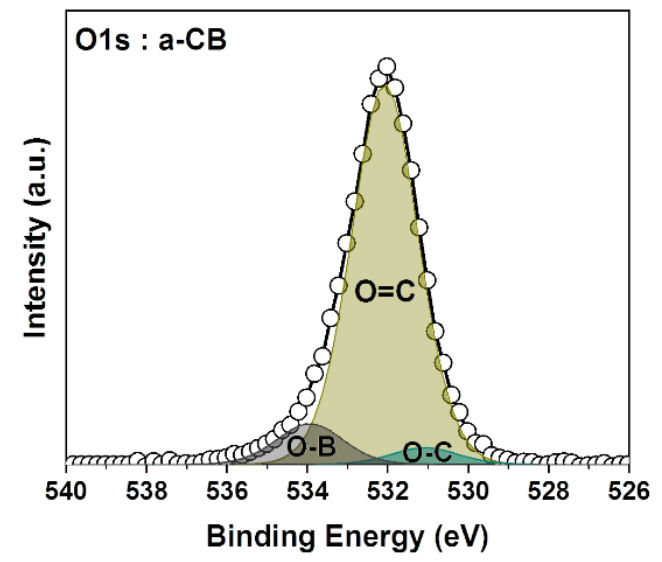

Figure 2. (a) XPS-B1s, (b) XPS-C1s spectrum, (c) XPS-O1s spectrum. All spectra are for a-C:B (9 at. $\%$.

In the a-C:B film, the B1s contributions (Figure 2a), centered at 188.8 and $191.2 \mathrm{eV}$, are assigned to $\mathrm{BC}_{3}$ and $\mathrm{BC}_{2} \mathrm{O}$ respectively. The $\mathrm{C} 1$ contributions (Figure 2b), centered at 283.8, 284.7, 286.4 and $287.6 \mathrm{eV}$, are respectively assigned to C-B (peak related to B-doped structure, 
indicating the successful doping of $\mathrm{B}$ ), $\mathrm{sp}^{2}$ carbon (typically observed in diamond-like carbon films), $\mathrm{C}-\mathrm{O}$ and $\mathrm{C}=\mathrm{O}$ species. The $\mathrm{O} 1$ core level spectrum (Figure 2c) shows the deconvoluted peaks at about 531, 532, and $533.9 \mathrm{eV}$ are associated respectively with $\mathrm{O}-\mathrm{C}, \mathrm{O}=\mathrm{C}$, and $\mathrm{O}-\mathrm{B}$ bonds.
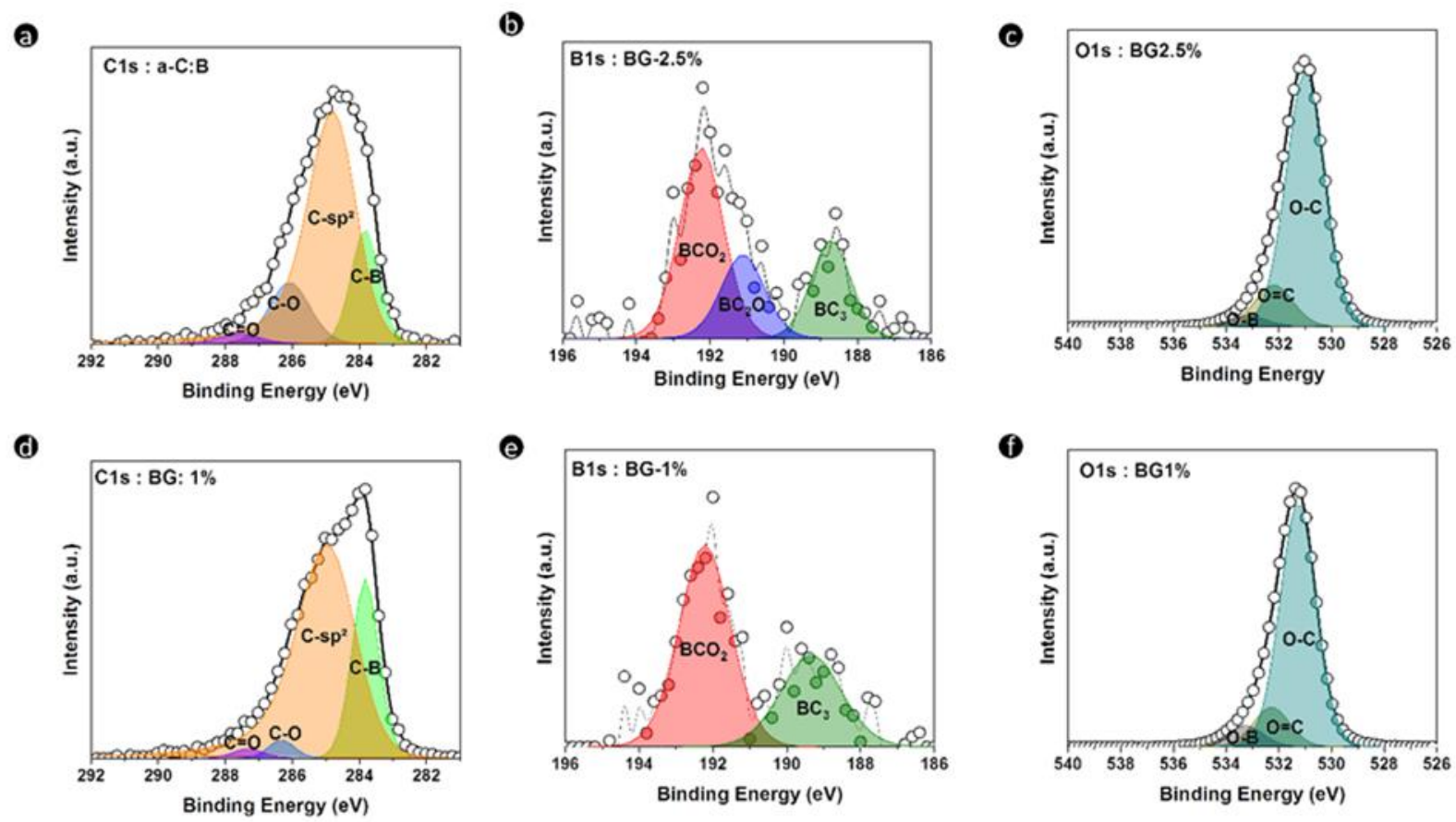

Figure 3. High resolution XPS spectra of BG (2.5 at.\%): (a) C1s, (b) B1s, (c) O1s. High-resolution XPS spectra of BG (1 at. \%): (d) C1s, (e) B1s, (f) O1s.

The high-resolution XPS spectra of $\mathrm{C} 1 \mathrm{~s}, \mathrm{~B} 1 \mathrm{~s}$, and $\mathrm{O} 1 \mathrm{~s}$ for $\mathrm{BG} 2.5 \%$ and $\mathrm{BG} 1 \%$ are reported in Figure 3. Indeed, after the conversion of $\mathrm{a}-\mathrm{C}: \mathrm{B}$ films into $\mathrm{BG}$ films using rapid thermal annealing, the position of the $\mathrm{C} 1$ contributions was not significantly modified. A relative increase in the C-B contribution was observed that could be due to the good incorporation of boron atom in the carbon network upon annealing. However, the possibility that this contribution includes some species of carbon dissolved in nickel cannot be excluded, as reported in our previous work [36]. Moreover, an increase in the $\mathrm{C}-\mathrm{O}$ and $\mathrm{C}=\mathrm{O}$ contributions was observed in $\mathrm{BG} 2.5 \%$, in agreement with the higher contribution of O1s. Concerning the boron signal, in BG2.5\%, the B1 contribution fit three peaks centered at 188.8, 191.1, and 192.2 $\mathrm{eV}$, assigned to $\mathrm{BC}_{3}, \mathrm{BC}_{2} \mathrm{O}$, and $\mathrm{BCO}_{2}$ respectively. In $\mathrm{BG} 1 \%$, the deconvolution of $\mathrm{B} 1 \mathrm{~s}$ rather gives two boron species $\mathrm{BC}_{3}(189.3 \mathrm{eV})$ and $\mathrm{BCO} 2(192.2 \mathrm{eV})$. In any case, the presence of $\mathrm{BC}_{3}, \mathrm{BC}_{2} \mathrm{O}$ and $\mathrm{BCO}_{2}$ bonds suggests carbon atoms were replaced by boron atoms in the 
graphene network, as reported in most of the references concerning BG films cited above. The $\mathrm{O} 1$ core level spectra (Figure 3c, f) show the same oxygen bonds $\mathrm{O}-\mathrm{C}, \mathrm{O}=\mathrm{C}$, and $\mathrm{O}-\mathrm{B}$ as those observed in a-C:B films. The relative abundance of oxygen in boron- and carbon-containing chemical groups is typical of top-surface compositions. The positions and FWHM of the carbon, boron and oxygen components derived from our fittings are summarized in Table 1.

\begin{tabular}{|c|c|c|c|c|c|c|c|c|c|c|c|}
\hline \multirow{2}{*}{\multicolumn{2}{|c|}{ Samples }} & \multicolumn{4}{|c|}{ C functional groups } & \multicolumn{3}{|c|}{ B functional groups } & \multicolumn{3}{|c|}{ O functional groups } \\
\hline & & C-B & $\mathrm{Csp}^{2}$ & $\mathrm{C}-\mathrm{O}$ & $\mathrm{C}=\mathrm{O}$ & $\mathrm{BC}_{3}$ & $\mathrm{BC}_{2} \mathrm{O}$ & $\mathrm{BCO}_{2}$ & $\mathrm{O}-\mathrm{C}$ & $\mathrm{O}=\mathrm{C}$ & $\mathrm{O}=\mathrm{B}$ \\
\hline \multirow[t]{2}{*}{$\mathrm{a}-\mathrm{C}: \mathrm{B}$} & $\begin{array}{l}\text { Position } \\
(\mathrm{eV})\end{array}$ & 283.8 & 284.7 & 286.4 & 287.6 & 188.8 & 191.2 & I & 531 & 532 & 533.9 \\
\hline & $\begin{array}{l}\text { FWHM } \\
(\mathrm{eV})\end{array}$ & 1.4 & 1.7 & 1.8 & 1.9 & 2.2 & 3.3 & l & 1.9 & 1.9 & 1.9 \\
\hline \multirow[t]{2}{*}{ BG1\% } & $\begin{array}{l}\text { Position } \\
(\mathrm{eV})\end{array}$ & 283.8 & 284.8 & 286.3 & 287.3 & 189.3 & I & 192.2 & 531.2 & 532.3 & 533.2 \\
\hline & $\begin{array}{l}\text { FWHM } \\
(\mathrm{eV})\end{array}$ & 1 & 1.8 & 1.1 & 1.3 & 2 & I & 3.7 & 1.6 & 1.6 & 1.6 \\
\hline \multirow[t]{2}{*}{ BG2.5\% } & $\begin{array}{l}\text { Position } \\
(\mathrm{eV})\end{array}$ & 283.8 & 284.7 & 286.1 & 287.5 & 188.8 & 191.1 & 192.2 & 531 & 532.2 & 533.2 \\
\hline & $\begin{array}{l}\text { FWHM } \\
(\mathrm{eV})\end{array}$ & 1 & 1.6 & 1.4 & 1.4 & 1.3 & 1.2 & 2.8 & 1.7 & 1.7 & 1.7 \\
\hline
\end{tabular}

Table 1. Summary of the positions and FWHM of the carbon, boron and oxygen functional groups derived from our fittings. The $\mathrm{Csp}^{2}$ was fitted using an asymmetric line whereas we used the Gaussian - Lorentzian (GL30) line for the other peaks.

The samples were also characterized by Raman spectroscopy and mapped to study the effect of boron doping on the synthesized graphene. In graphene-based materials, the D, G, and 2D bands are the most significant features observed in Raman spectroscopy. The $\mathrm{G}$ band appears around $1580 \mathrm{~cm}^{-1}$ and is associated with covalent $\mathrm{C}-\mathrm{C}$ bonding vibrations in the graphite matrix and is /was present in every carbon material containing $\mathrm{sp}^{2}$ bonding. The $\mathrm{D}$ band, located around 1 $350 \mathrm{~cm}^{-1}$, is associated with the pulsation of aromatic circles, and only appeared in the presence of defects and dislocations in the graphitic matrix [48-50]. The intensity ratio between the D band and $G$ band $\left(\mathrm{I}_{\mathrm{D}} / \mathrm{I}_{\mathrm{G}}\right)$ is thus an indication of disorder in the graphene structure. The $2 \mathrm{D}$ band is situated around $2700 \mathrm{~cm}^{-1}$ and is associated with a double resonance Raman scattering process. With graphene-based materials, the intensity ratio of the $2 \mathrm{D}$ band versus the $\mathrm{G}$ band $\left(\mathrm{I}_{2 \mathrm{D}} / \mathrm{I}_{\mathrm{G}}\right)$ is a good indicator to identify the number of graphene layers. It is generally accepted that an $\mathrm{I}_{2 \mathrm{D}} / \mathrm{I}_{\mathrm{G}}$ ratio $>1.4$ represents the formation of monolayer graphene. Bilayer graphene can be identified by an $\mathrm{I}_{2 \mathrm{D}} / \mathrm{I}_{\mathrm{G}}$ ratio of between 0.75 and 1.4 , and graphene with three and more layers can be identified by an $\mathrm{I}_{2 \mathrm{D}} / \mathrm{I}_{\mathrm{G}}$ ratio $<0.75[\mathbf{5 1 - 5 3}]$. 
Here, the Raman mapping of $20 \times 20 \mu \mathrm{m}^{2}$ (each integrating 400 Raman spectra) was performed on representative areas of the undoped and boron-doped graphene samples with 1 and 2.5 at.\%, and the maps were processed for the $\mathrm{I}_{\mathrm{D}} / \mathrm{I}_{\mathrm{G}}$ and $\mathrm{I}_{2 \mathrm{D}} / \mathrm{I}_{\mathrm{G}}$ intensity ratios, $2 \mathrm{D}$ peak FWHM, and crystallite size $\mathrm{L}_{\mathrm{a}}$, as well as $\mathrm{G}$, and 2D peak positions as shown in Figure 4. Table 2 lists the average values plus standard deviations of the $\mathrm{I}_{\mathrm{D}} / \mathrm{I}_{\mathrm{G}}, \mathrm{I}_{2 \mathrm{D}} / \mathrm{I}_{\mathrm{G}}, 2 \mathrm{D}(\mathrm{FWHM}), \mathrm{L}_{\mathrm{a}}, \mathrm{G}$, and $2 \mathrm{D}$ positions taken from the Raman maps of each sample.

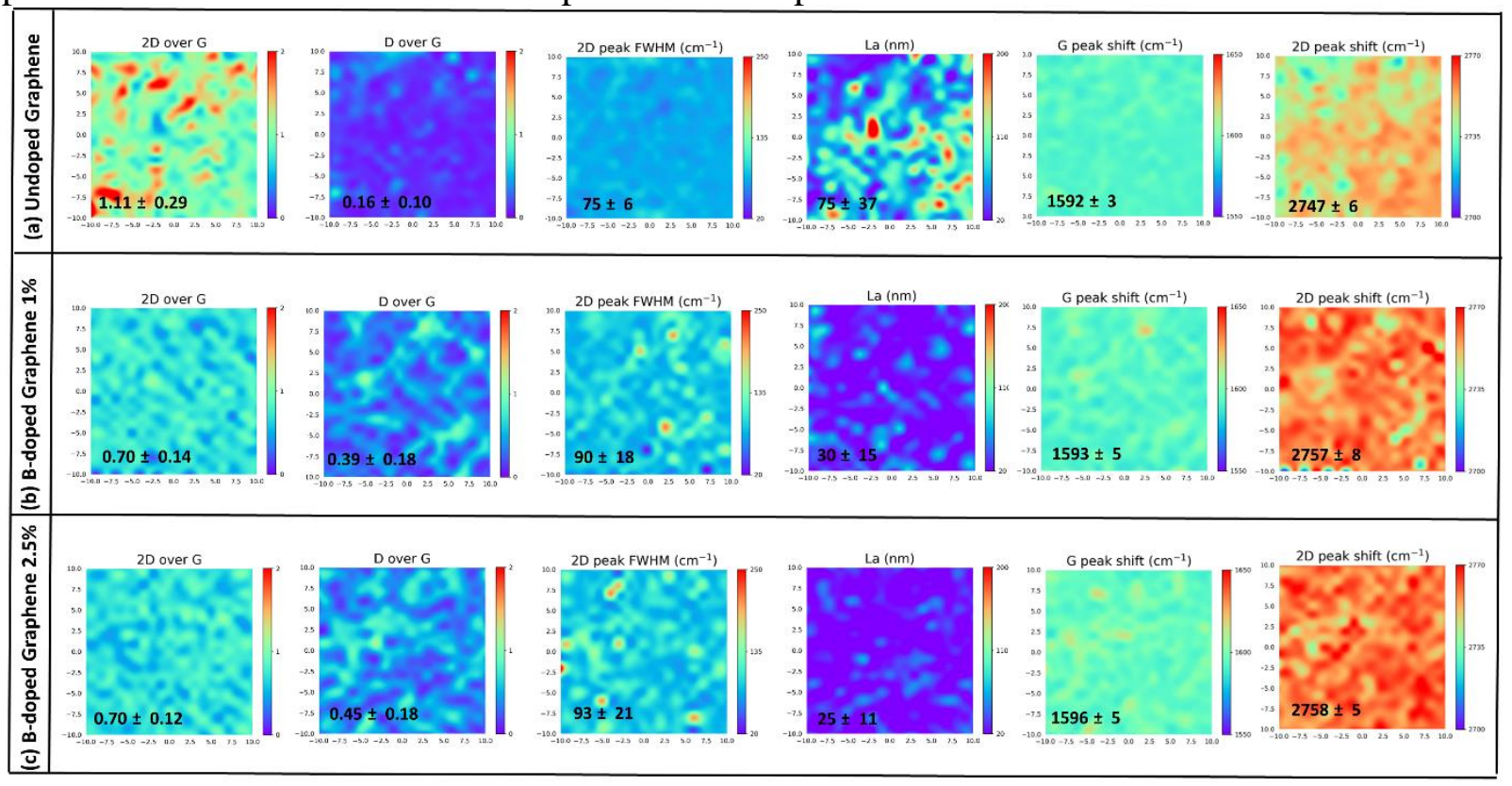

Figure 4. $\mathrm{I}_{\mathrm{D}} / \mathrm{I}_{\mathrm{G}}, \mathrm{L}_{\mathrm{a}}, \mathrm{I}_{2 \mathrm{D}} / \mathrm{I}_{\mathrm{G}}, 2 \mathrm{D}$ (FWHM), $2 \mathrm{D}$ and $\mathrm{G}$ positions on Raman maps of (a) undoped graphene, (b) boron-doped graphene $1 \%$, (c) boron-doped graphene $2.5 \%$, with their average values.

\begin{tabular}{|l|l|l|l|l|l|l|}
\hline & $\mathrm{I}_{\mathrm{D}} / \mathrm{I}_{\mathrm{G}}$ & $\mathrm{L}_{\mathrm{a}}(\mathrm{nm})$ & $\mathrm{I}_{2 \mathrm{D}} / \mathrm{I}_{\mathrm{G}}$ & $\begin{array}{l}2 \mathrm{D}(\mathrm{FWHM}) \\
\left(\mathrm{cm}^{-1}\right)\end{array}$ & $\begin{array}{l}2 \mathrm{D} \text { position } \\
\left(\mathrm{cm}^{-1}\right)\end{array}$ & $\begin{array}{l}\mathrm{G}^{-1} \\
\left(\mathrm{~cm}^{-1}\right)\end{array}$ \\
\hline $\mathrm{G}$ & $0.16 \pm 0.10$ & $75 \pm 37$ & $1.11 \pm 0.29$ & $75 \pm 6$ & $2,747 \pm 6$ & $1,592 \pm 3$ \\
\hline BG1\% & $0.39 \pm 0.18$ & $30 \pm 15$ & $0.70 \pm 0.14$ & $90 \pm 18$ & $2,757 \pm 8$ & $1,593 \pm 5$ \\
\hline BG2.5\% & $0.45 \pm 0.18$ & $25 \pm 11$ & $0.70 \pm 0.12$ & $93 \pm 21$ & $2,758 \pm 5$ & $1,596 \pm 5$ \\
\hline
\end{tabular}

Table 2. Average values plus standard deviations of the Raman characteristics resulting from the 400 Raman spectra performed on representative areas of the synthesized undoped and boron graphene.

It is worth noting that the crystallite size (La) was deduced from ID/IG intensity ratio using using the Tuinstra-Koenig relation[54]: $\mathrm{L}_{\mathrm{a}}(\mathrm{nm})=\left(2,4 \times 10^{-10}\right) \lambda^{4}\left(\frac{\mathrm{I}_{\mathrm{D}}}{\mathrm{I}_{\mathrm{G}}}\right)^{-1}$ with $\lambda$ the laser wavelength in nanometer units.

We observed that the average value of the $\mathrm{I}_{\mathrm{D}} / \mathrm{I}_{\mathrm{G}}$ intensity ratio increased with an increase in boron doping from 0.16 to 0.45 . In addition, a decrease in the average value of the crystallite 
size ( $\mathrm{L}_{\mathrm{a}}$ ) from 75 to $25 \mathrm{~nm}$ was observed with an increase in the level of boron doping. These results suggest that boron doping increased the density of defects in the graphene structure and reduced the crystallite size of graphene, in agreement with the results of previous reported studies on boron doped graphene[4,17,47]. In addition, the average value of the $\mathrm{I}_{2 \mathrm{D}} / \mathrm{I}_{\mathrm{G}}$ intensity ratio decreased from 1.11 to 0.70 with boron doping, whereas the average value of FWHM (2D) increased from 75 to $93 \mathrm{~cm}^{-1}$.
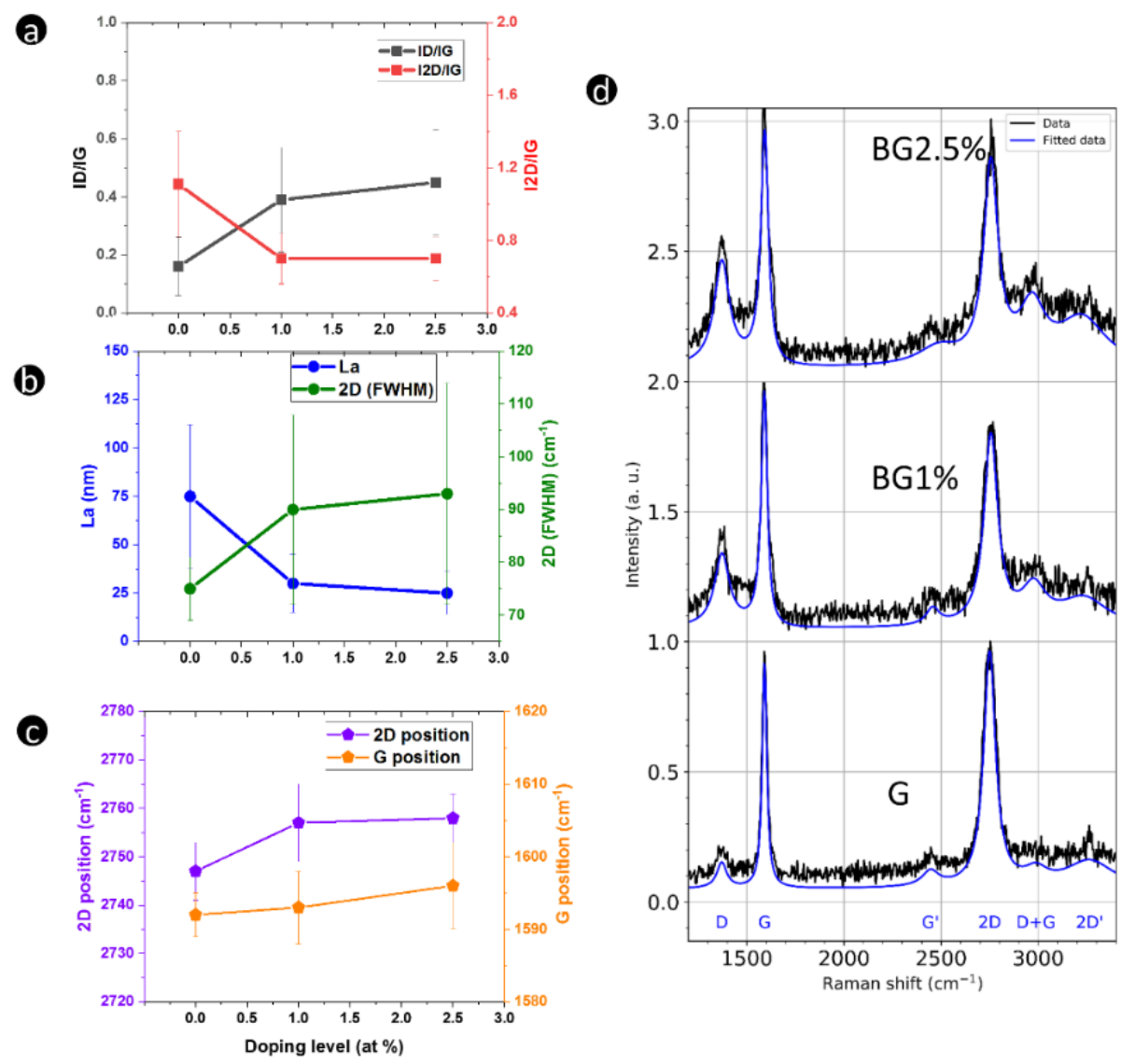

Figure 5. Plots showing dependence on the boron doping level as a function of the average value of (a) $\mathrm{I}_{\mathrm{D}} / \mathrm{I}_{\mathrm{G}}$ ratio, $\mathrm{I}_{2 \mathrm{D}} / \mathrm{I}_{\mathrm{G}}$ ratio, (b) crystallite size (La), the FWHM (2D), and (c) positions of the $\mathrm{G}$ and $2 \mathrm{D}$ peaks for the synthesized undoped and boron-doped graphene (1, 2.5 at\%). (d) Typical experimental (black) and fitted (blue) Raman spectra of the synthesized undoped and boron-doped graphene films $(1,2.5$ at.\%).

We observed a slight change in the position of $G$ and 2D peaks as a function of the level of boron doping. Indeed, the $\mathrm{G}$ peak shifted slightly upward with an increase in the level of boron doping. It is worth noting that this upshift of the $G$ peak could be due either to a reduction in the size of the graphene crystallite [56], or to the effect of doping [57], or to the influence of compressive stress [58-60]. It is therefore not easy to conclude that the upshift of the Geak is only due to the boron doping effect. However, we clearly observed that boron doping markedly 
influenced the structure of the graphene. Concerning the 2D peak, we also observed an upshift from 2,747 to 2,758 $\mathrm{cm}^{-1}$ with boron doping. All these effects are illustrated in Figures 5a-c with the plot of $\mathrm{I}_{\mathrm{D}} / \mathrm{I}_{\mathrm{G}}$ and $\mathrm{I}_{2 \mathrm{D}} / \mathrm{I}_{\mathrm{G}}$ ratios and crystallite size $\mathrm{L}_{\mathrm{a}}$ and FWHM (2D) as well as the positions of the $\mathrm{G}$ and $2 \mathrm{D}$ peaks as a function of the boron doping level. As observed for the average value of the different maps, the intensity of the $\mathrm{I}_{\mathrm{D}} / \mathrm{I}_{\mathrm{G}}$ and $\mathrm{I}_{2 \mathrm{D}} / \mathrm{I}_{\mathrm{G}}$ ratios evolved in the opposite way with an increase in the level of boron doping. The crystallite size $L_{a}$ and the FWHM (2D) also displayed the opposite trend with boron doping, whereas the position of the $\mathrm{G}$ and 2D peaks rather followed the same trend. Further, it is worth underlining that the high values of the standard deviations for all the maps demonstrate that the number of layers, the density of defects, and the size of the crystallites in the synthesized undoped and boron-doped graphene are rather heterogeneous. Figure 5d shows some typical Raman spectra extracted from the map of each of the samples detailed in Table 2. The main peaks characteristic of graphene $\mathrm{D}, \mathrm{G}$, and $2 \mathrm{D}$ are visible. We observed that the $\mathrm{D}$ peak became more intense with boron doping, suggesting the existence of a high density of defects in the BG films. Taking into consideration the results of XPS and Raman analysis and interpretations, we have demonstrated that an amorphous a-C:B film obtained by co-ablation of carbon and boron can be thermally converted into a boron-doped graphene film containing a lower boron content than in the precursor film. In the following section, we highlight the electrochemical performance of these BG films.

\subsection{Electrochemistry response of our synthesized $\mathrm{G}$ and $\mathrm{BG}$ films}

\section{a. Results of cyclic voltammetry}

Cyclic voltammetry (CV) was performed on the synthesized graphene (sample G) and borondoped graphene containing the two boron doping levels 0,1 (BG1\%) and 2.5 at.\% (BG2.5\%). At this stage, it is worth mentioning that all the cyclic voltammetry measurements were performed on the as-grown undoped and boron-doped graphene. However, during the CV measurements, the signal of these nickel residuals was not observed with CV analysis, suggesting that the presence of these nickel residuals does not influence the electrochemical results. Cyclic voltammetry (CV) measurements obtained with ferrocene dimethanol on undoped graphene $(\mathrm{G})$ and B-doped graphene $(\mathrm{BG})$ at the scan rate of $50 \mathrm{mV} \mathrm{s}^{-1}$ are presented in Figure 6, and the comparative electrochemical parameters are listed in Table 3. 
The values of the potential separation between the oxidation and reduction peak $\Delta \mathrm{E}$ for $\mathrm{G}$, BG1\%, and $\mathrm{BG} 2.5 \%$ were respectively $0.35,0.17$, and $0.20 \mathrm{~V}$, demonstrating that the two boron-doped graphene electrodes exhibit higher reversibility and better kinetic electronic transfer than the undoped graphene electrode. However, these measurements also show that the electronic transfers are quasi-reversible and not Nernstian $(\Delta \mathrm{E} \sim 59 \mathrm{mV})$. In addition, we observed an increase in both oxidation and reduction currents with an increase in the concentration of boron, in agreement with the results of a previous study on BG film [4]. The two boron-doped graphene electrodes present higher faradaic current than the undoped graphene due to the redox molecule. This also suggests that the electrochemical properties of BG electrodes are better than those of undoped graphene.
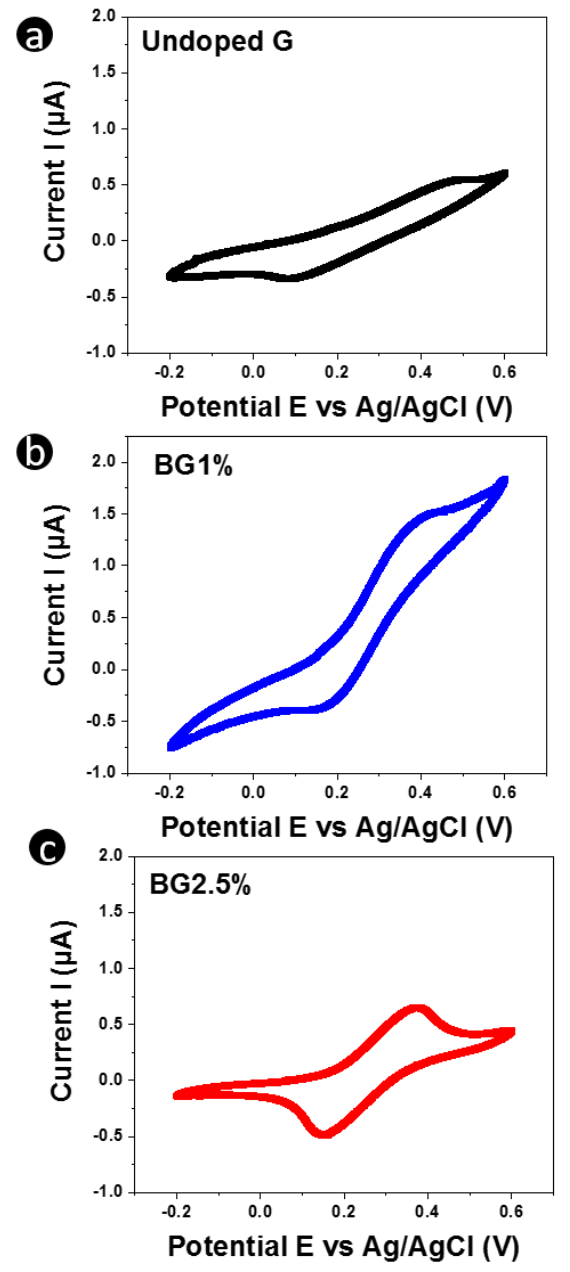

Figure 6. Cyclic voltammetry curves measured in a $0.5 \mathrm{M} 1,1$ ferrocene-dimethanol solution of $0.1 \mathrm{M}$ $\mathrm{NaClO}_{4}$ with a scan rate of $50 \mathrm{mV} / \mathrm{s}$. (a) CV of undoped graphene. (b) $\mathrm{CV}$ of BG1\%. (c) CV of BG2.5\%.

\begin{tabular}{|l|c|r|r|r|r|r|}
\hline Samples & $\mathrm{B}($ at. $\%)$ & $\mathrm{E}_{\text {ox }}(\mathrm{V})$ & $\mathrm{E}_{\text {red }}(\mathrm{V})$ & $\mathrm{I}_{\text {ox* }}(\mu \mathrm{A})$ & $\mathrm{I}_{\text {red* }}(\mu \mathrm{A})$ & $\Delta \mathrm{E}(\mathrm{V})$ \\
\hline $\mathrm{G}$ & 0 & 0.46 & 0.11 & 0.09 & 0.15 & 0.35 \\
\hline
\end{tabular}




\begin{tabular}{|l|c|r|r|r|r|r|}
\hline BG & 1 & 0.36 & 0.19 & 0.38 & 0.44 & 0.17 \\
\hline BG & 2.5 & 0.36 & 0.16 & 0.40 & 0.47 & 0.20 \\
\hline
\end{tabular}

Table 3. Results of electrochemical measurements on $B G$ and undoped graphene films. *: $I_{o x}$ and $I_{\text {red }}$ correspond to the integrated area under the peak and not the $\mathrm{I}_{\max }$.

To estimate the kinetic rate of interfacial electron transfer constant $\mathrm{k}_{0}$, the dimensionless kinetic parameter $\Psi$ was first determined using the method developed by Lavagnini [61] for a quasireversible system with $\Delta \mathrm{E}$ values higher than $200 \mathrm{mV}$ using the following equation:

$$
\Psi=2.18[\beta / \pi]^{1 / 2} \exp \left[-\left(\beta^{2} F / R T\right) n \Delta E\right]
$$

where $\Psi$ is a kinetic parameter, $\mathrm{n}$ is the number of electrons involved in the process $(\mathrm{n}=1), \mathrm{F}$ is the Faraday constant $\left(\mathrm{F}=96485 \mathrm{C} \cdot \mathrm{mol}^{-1}\right), \mathrm{R}$ the gas constant $\left(\mathrm{R}=8.314 \mathrm{~J} \cdot \mathrm{mol}^{-1} \mathrm{~K}^{-1}\right)$, T the temperature $(\mathrm{T}=298 \mathrm{~K}), \beta$ the transfer coefficient generally assumed to be $0.5[\mathbf{6 2}, \mathbf{6 3}]$ and $\Delta \mathrm{E}$ is the peak-to-peak separation in volts. A plot of $\Psi$ versus $v^{-1 / 2}(\mathrm{v}$ being the experimental CV scan rate) then allows the electron transfer rate constants $\mathrm{k}_{\mathrm{o}}$ to be determined through the slope of the linear fit. Indeed, to calculate the kinetic parameter $\Psi$, the voltammetry curves were recorded for each sample at different scan rates ranging from 2 to $200 \mathrm{mV} / \mathrm{s}$. Next, we plot the calculated kinetic parameter $(\Psi)$ versus the reverse of the square root of the scan rate $\left(v^{-1 / 2}\right)$, as shown in Figure 7.

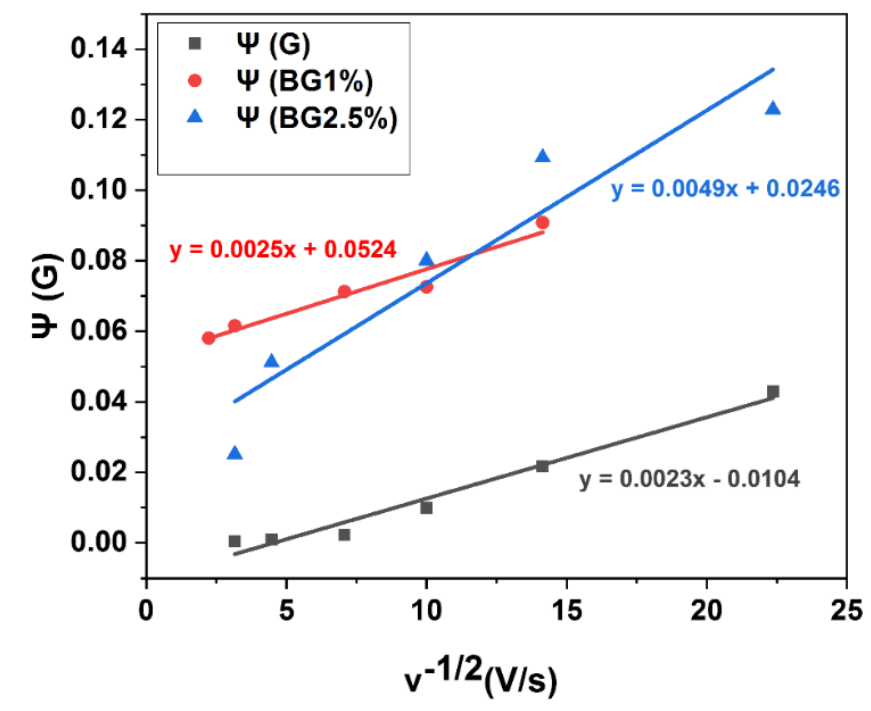

Figure 7. The plot of $\Psi$ versus $v^{-1 / 2}$ enabling the estimation of the kinetic rate of interfacial electron transfer constant $\mathrm{k}_{\mathrm{o}}$. 
Consequently, $\mathrm{k}_{\mathrm{o}}$ was found to be equal to $2.3 \times 10^{-3}, 2.5 \times 10^{-3}$, and $4.9 \times 10^{-3} \mathrm{~cm} . \mathrm{s}^{-1}$ for undoped graphene $\mathrm{G}, \mathrm{BG} 1 \%$, and $\mathrm{BG} 2.5 \%$ respectively. It is clear from these results that undoped graphene possesses the smallest $\mathrm{k}_{\mathrm{o}}$ thereby pointing to reduced electron transfer properties. Although the increase due to a boron doping level of $1 \%$ seems very limited, increasing the boron doping level up to $2.5 \%$ almost doubles the $\mathrm{k}_{\mathrm{o}}$ value. All these results show that the electrochemical performance of $\mathrm{BG} 2.5 \%$ with respect to $\mathrm{BG} 1 \%$ is better, probably due to the higher concentration of boron content defects of BG2.5\%, which can facilitate the transfer of charge between neighboring carbon atoms in a graphene lattice $[\mathbf{4 5 , 6 2}]$.

b. Relation between boron doping and electron transfer capability

To correlate the nanostructure of the undoped and boron-doped graphene with the kinetic rate of interfacial electron transfer $\left(k_{o}\right)$, the average $I_{D} / I_{G}$ intensity ratios calculated in the Raman analysis section above are linked to the electron transfer constant $\mathrm{k}_{\mathrm{o}}$ values and shown in Figure 3.

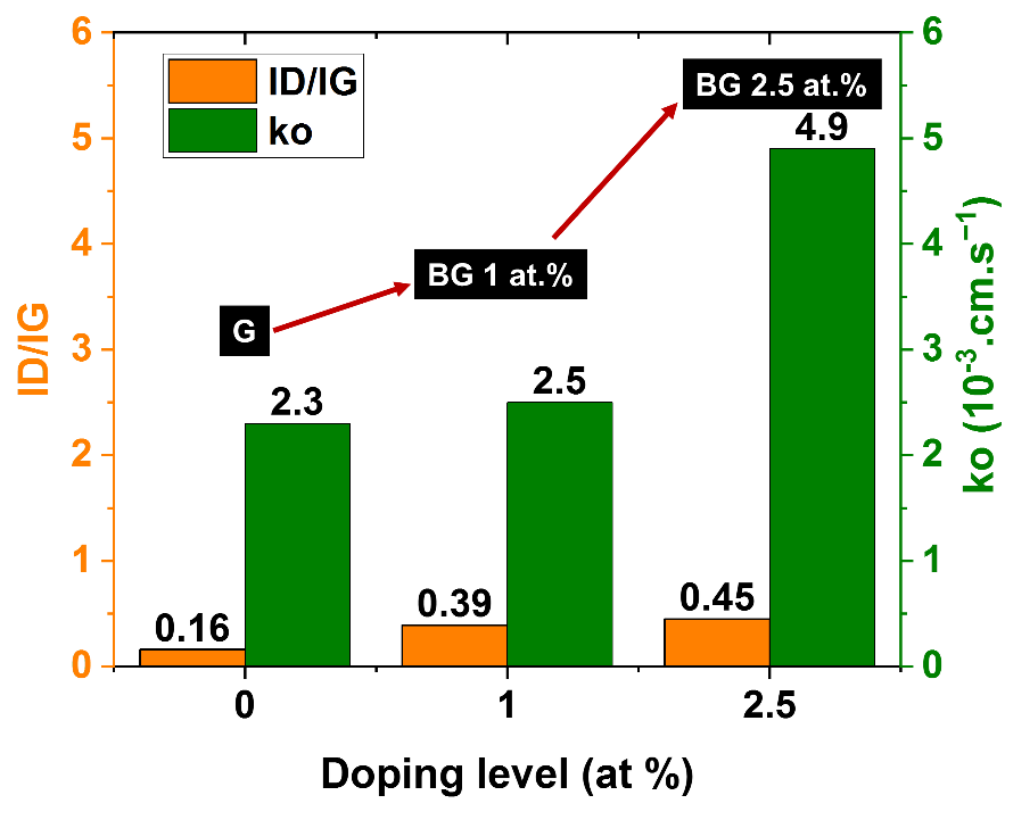

Figure 8: The correlation between the kinetic rate of interfacial electron transfer $\left(\mathrm{k}_{\mathrm{o}}\right)$ and the average intensity ratio of the $\mathrm{D}$ peak over the $\mathrm{G}$ peak $\left(\mathrm{I}_{\mathrm{D}} / \mathrm{I}_{\mathrm{G}}\right)$ of the $\mathrm{G}, \mathrm{BG} 1 \%$ and $\mathrm{BG} 2.5 \%$.

Figure 8 shows the correlation between the $k_{o}$ and the average $I_{D} / I_{G}$ values. When a boron concentration was introduced in the graphene structure, the $\mathrm{I}_{\mathrm{D}} / \mathrm{I}_{\mathrm{G}}$ ratio increased from 0.16 to 0.39 , indicating increased disorder in the graphene material. Nevertheness, there was no significant effect on the electron transfer constant $\mathrm{k}_{0}$ with very little change from $2.3 .10^{-3}$ to 2.5. $10^{-3} \mathrm{~cm} . \mathrm{s}^{-1}$. Then, by increasing the boron concentration from 1 to 2.5 at. $\%$, we observed 
much more disorder and the electron transfer constant almost doubled from 2.5. 10 ${ }^{-3}$ to $4.9 .10^{-}$ ${ }^{3} \mathrm{~cm} . \mathrm{s}^{-1}$. This suggests that the interfacial electron transfer capability depends not only on the defects present in the graphene material in agreement with our previous work on CVD graphene [64], but more importantly on the concentration of dopant. Indeed, it is well known that pristine graphene does not present good interfacial electron transfer kinetics, but that an appropriate concentration of dopant leading to an appropriate density of defects can significantly improve the electrochemical activity of graphene, as we observed in the present study. For further analysis, BG2.5\% was used for the stability study, as described below.

c. Stability study of the Boron doped graphene with 2.5 at.\%

For the stability study, the CV curves were recorded for different lengths of time in the redox probe. Figures 9a-b show the CV curves of BG2.5\% for the different lengths of time in ferrocene dimethanol. Several cycles were performed at $50 \mathrm{mV} / \mathrm{s}$.
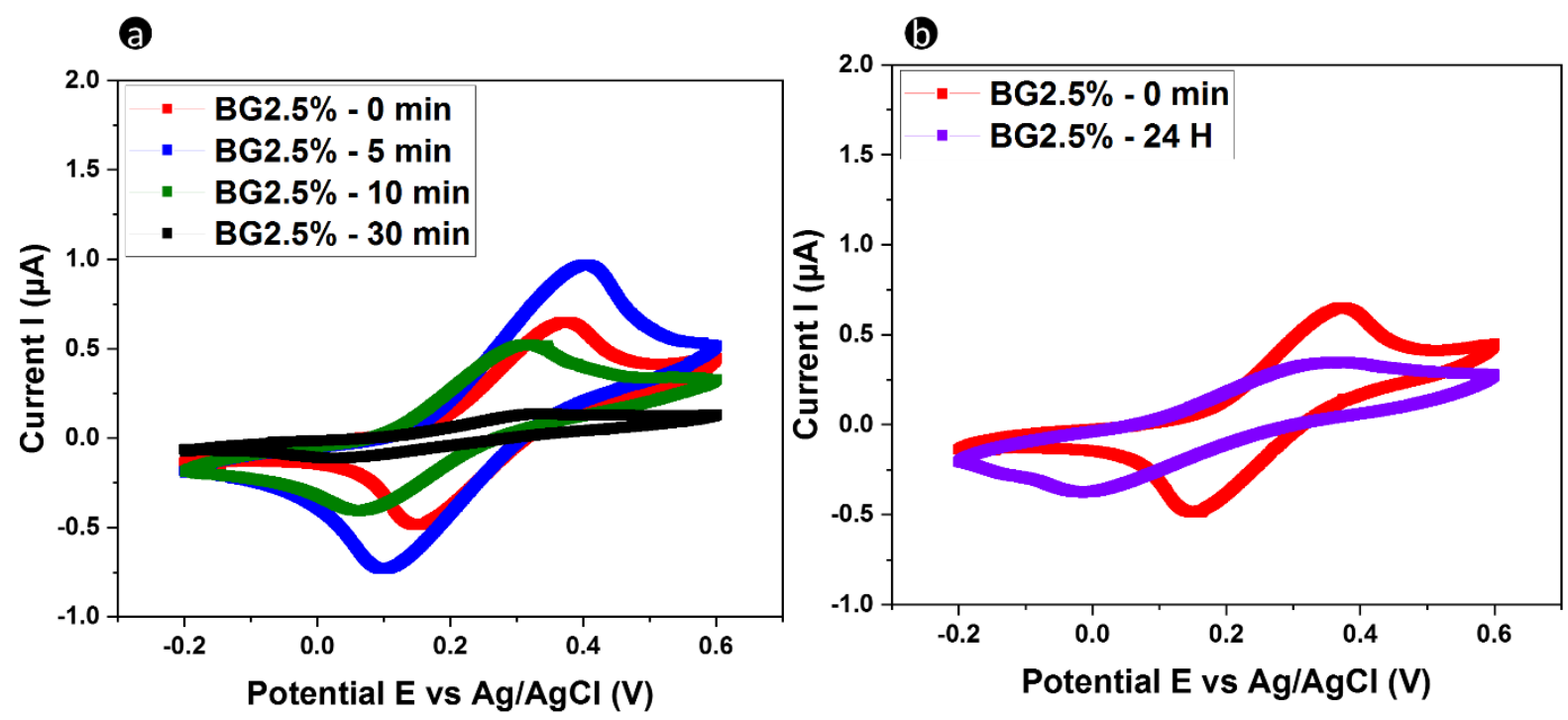

Figure 9. Cyclic voltammetry on BG20 in a $0.5 \mathrm{M}$ 1'ferrocene-dimethanol solution of $0.1 \mathrm{M} \mathrm{NaClO}_{4}$ (a) at $0 \mathrm{~min}$ (red), and after $5 \mathrm{~min}$ (blue), $10 \mathrm{~min}$ (green), and $30 \mathrm{~min}$ (black) of incubation; (b) at $0 \mathrm{~min}$ (red) and after 24 hours of incubation (purple). The scan rate is $50 \mathrm{mV} / \mathrm{s}$.

Figure 9a shows that the intensity of oxidation and reduction current signal decreases with time and the number of cycles, from 0 to 30 minutes of cycling. Indeed, initially, the fresh BG2.5\% electrode presents a redox behavior with the fastest kinetics (highest peak currents) (red curve). By increasing the length of time in the ferrocene dimethanol electrolyte, the peak currents were reduced, especially at $10,30 \mathrm{~min}$, and $\Delta \mathrm{E}$ values increased slightly except for the period 
lasting10 minutes. This could be due to the number of cycles, which can also affect the sensitivity of the BG film. It is worth mentioning that the values of potential and currents of BG2.5\% in Table 4 differed slightly from those listed in Table 3 because the measurements were not taken at exactly the same location, evidence for heterogeneous Raman mapping.

\begin{tabular}{|c|r|r|r|r|r|}
\hline Time $(\min )$ & $\mathrm{E}_{\mathrm{ox}}(\mathrm{V})$ & \multicolumn{1}{c|}{$\mathrm{E}_{\text {red }}(\mathrm{V})$} & $\mathrm{I}_{\mathrm{ox}}(\mu \mathrm{A})$ & $\mathrm{I}_{\text {red }}(\mu \mathrm{A})$ & \multicolumn{1}{c|}{$\Delta \mathrm{E}(\mathrm{V})$} \\
\hline 0 & 0.37 & 0.15 & 0.43 & 0.56 & 0.22 \\
\hline 5 & 0.39 & 0.11 & 0.63 & 0.68 & 0.28 \\
\hline 10 & 0.30 & 0.06 & 0.34 & 0.56 & 0.24 \\
\hline 30 & 0.32 & 0.03 & 0.08 & 0.09 & 0.29 \\
\hline 1,440 & 0.315 & -0.00536 & 0.168 & 0.198 & 0.320 \\
\hline
\end{tabular}

Table 4. Results of electrochemical measurements on BG2.5\% for different lengths of time in ferrocene dimethanol at a scan rate of $50 \mathrm{mV} / \mathrm{s}$.

Figure 9b shows the results of a complementary stability study in which the sample was left in the cell in case the curve (black curve) - that was initially very reversible - tended to widen and increasingly resemble the signal of undoped graphene. Indeed, the peak currents significantly decreased while the $\Delta \mathrm{E}$ value increased to approach that of undoped graphene. The cumulative effect of cycling ( 20 cycles in the same area) and incubation in the solution for 24 hours $(1,440 \mathrm{~min})$ seemed to affect the electrochemical response. However, even though the peak currents decreased, the peak potential of the BG2.5\% electrode with 5, 10, 30, and 1,440 min duration only shifted slightly. This means the kinetic rate did not change significantly, and that the decrease in the peak current could be due to the reduction in the apparent geometric area of the BG2.5\% electrode. These results thus demonstrate that the length and the number of cycles affect the preservation stability of BG2.5\%. Adhesion of the conductive layer to the support is probaby not sufficient to resist the successive cycles of potential achieved during the measurements. Thus, the stability of the BG electrode over time requires further improvement.

\section{Conclusion}

The present study addresses the relationship between the chemical composition and nanostructure of BG films produced using PLD, with their electrochemical properties. The film nanoarchitecture and chemical composition were investigated by combining Raman, and XPS. The synthesized boron-doped graphene films comprise a few layers with the control of boron content of about 1 and 2.5 at.\%. and with boron mainly bonded to carbon in both $\mathrm{BC}_{3}$ and $\mathrm{BCO}_{2}$ 
configurations and high density of defects associated with a reduction in the size of the cluster. Further, cyclic voltammetry measurements showed that boron doping enhances the electrochemical activity of the boron-doped graphene films. By increasing the doping level from 1 to 2.5 at.\%, the electron transfer becomes much higher, meaning that the electron transfer capability depends on the concentration of dopant. However, preserving the stability of the BG2.5\% electrode is time-dependent, and needs to be improved to achieve much greater stability over time. Finally, this work shows that boron doped graphene can be easily synthesized using PLD with promising applications in electrochemical devices such as fuel cells, batteries and biosensors.

\section{Acknowledgments}

This work was supported by the LABEX MANUTECH-SISE (ANR-10- LABX-0075) of University of Lyon, France, as part of the program "Investissements d'Avenir" (ANR-11-IDEX0007) operated by the French National Research Agency (ANR).

\section{References}

1. Wang, X.; Sun, G.; Routh, P.; Kim, D.-H.; Huang, W.; Chen, P. Heteroatom-doped graphene materials: syntheses, properties and applications. Chemical Society Reviews 2014, 43, 7067-7098, doi:10.1039/C4CS00141A.

2. Agnoli, S.; Favaro, M. Doping graphene with boron: a review of synthesis methods, physicochemical characterization, and emerging applications. J. Mater. Chem. A 2016, 4 , 5002-5025, doi:10.1039/C5TA10599D.

3. Rani, P.; Jindal, V.K. Designing band gap of graphene by $\mathrm{B}$ and $\mathrm{N}$ dopant atoms. RSC $A d v$. 2012, 3, 802-812, doi:10.1039/C2RA22664B.

4. Sheng, Z.-H.; Gao, H.-L.; Bao, W.-J.; Wang, F.-B.; Xia, X.-H. Synthesis of boron doped graphene for oxygen reduction reaction in fuel cells. J. Mater. Chem. 2011, 22, 390-395, doi:10.1039/C1JM14694G.

5. Lü, X.; Wu, J.; Lin, T.; Wan, D.; Huang, F.; Xie, X.; Jiang, M. Low-temperature rapid synthesis of high-quality pristine or boron-doped graphenevia Wurtz-type reductive coupling reaction. J. Mater. Chem. 2011, 21, 10685-10689, doi:10.1039/C1JM11184A.

6. Han, J.; Zhang, L.L.; Lee, S.; Oh, J.; Lee, K.-S.; Potts, J.R.; Ji, J.; Zhao, X.; Ruoff, R.S.; Park, S. Generation of B-Doped Graphene Nanoplatelets Using a Solution Process and Their Supercapacitor Applications. ACS Nano 2013, 7, 19-26, doi:10.1021/nn3034309.

7. Thirumal, V.; Pandurangan, A.; Jayavel, R.; Ilangovan, R. Synthesis and characterization of boron doped graphene nanosheets for supercapacitor applications. Synthetic Metals 2016, 220, 524-532, doi:10.1016/j.synthmet.2016.07.011.

8. Umrao, S.; Gupta, T.K.; Kumar, S.; Singh, V.K.; Sultania, M.K.; Jung, J.H.; Oh, I.-K.; Srivastava, A. Microwave-Assisted Synthesis of Boron and Nitrogen co-doped Reduced 
Graphene Oxide for the Protection of Electromagnetic Radiation in Ku-Band. ACS Appl. Mater. Interfaces 2015, 7, 19831-19842, doi:10.1021/acsami.5b05890.

9. Cattelan, M.; Agnoli, S.; Favaro, M.; Garoli, D.; Romanato, F.; Meneghetti, M.; Barinov, A.; Dudin, P.; Granozzi, G. Microscopic View on a Chemical Vapor Deposition Route to Boron-Doped Graphene Nanostructures. Chem. Mater. 2013, 25, 1490-1495, doi:10.1021/cm302819b.

10. Li, X.; Fan, L.; Li, Z.; Wang, K.; Zhong, M.; Wei, J.; Wu, D.; Zhu, H. Boron Doping of Graphene for Graphene-Silicon p-n Junction Solar Cells. Advanced Energy Materials 2012, 2, 425-429, doi:10.1002/aenm.201100671.

11. Zhao, L.; Levendorf, M.; Goncher, S.; Schiros, T.; Pálová, L.; Zabet-Khosousi, A.; Rim, K.T.; Gutiérrez, C.; Nordlund, D.; Jaye, C.; et al. Local Atomic and Electronic Structure of Boron Chemical Doping in Monolayer Graphene. Nano Lett. 2013, 13, 4659-4665, doi:10.1021/nl401781d.

12. Wang, H.; Zhou, Y.; Wu, D.; Liao, L.; Zhao, S.; Peng, H.; Liu, Z. Synthesis of BoronDoped Graphene Monolayers Using the Sole Solid Feedstock by Chemical Vapor Deposition. Small 2013, 9, 1316-1320, doi:10.1002/smll.201203021.

13. Usachov, D.Yu.; Fedorov, A.V.; Petukhov, A.E.; Vilkov, O.Yu.; Rybkin, A.G.; Otrokov, M.M.; Arnau, A.; Chulkov, E.V.; Yashina, L.V.; Farjam, M.; et al. Epitaxial B-Graphene: Large-Scale Growth and Atomic Structure. ACS Nano 2015, 9, 7314-7322, doi:10.1021/acsnano.5b02322.

14. Wang, L.; Zhang, X.; Yan, F.; Chan, H.L.W.; Ding, F. Mechanism of boron and nitrogen in situ doping during graphene chemical vapor deposition growth. Carbon 2016, 98, 633637, doi:10.1016/j.carbon.2015.11.058.

15. You, Y.; Wang, C.; Xu, Y.L.; Wan, J.X.; Ren, W.; Fang, X.H.; Chen, X.Y. Effects of growth conditions on the quality of B-doped graphene films. Journal of Applied Physics 2017, 121, 025305, doi:10.1063/1.4974010.

16. Boukhvalov, D.W.; Zhidkov, I.S.; Kukharenko, A.I.; Slesarev, A.I.; Zatsepin, A.F.; Cholakh, S.O.; Kurmaev, E.Z. Stability of boron-doped graphene/copper interface: DFT, XPS and OSEE studies. Applied Surface Science 2018, 441, 978-983, doi:10.1016/j.apsusc.2018.02.074.

17. Panchakarla, L.S.; Subrahmanyam, K.S.; Saha, S.K.; Govindaraj, A.; Krishnamurthy, H.R.; Waghmare, U.V.; Rao, C.N.R. Synthesis, Structure, and Properties of Boron- and Nitrogen-Doped Graphene. Advanced Materials 2009, 21, 4726-4730, doi:10.1002/adma.200901285.

18. Wu, Z.-S.; Ren, W.; Xu, L.; Li, F.; Cheng, H.-M. Doped Graphene Sheets As Anode Materials with Superhigh Rate and Large Capacity for Lithium Ion Batteries. ACS Nano 2011, 5, 5463-5471, doi:10.1021/nn2006249.

19. Kim, Y.A.; Fujisawa, K.; Muramatsu, H.; Hayashi, T.; Endo, M.; Fujimori, T.; Kaneko, K.; Terrones, M.; Behrends, J.; Eckmann, A.; et al. Raman Spectroscopy of Boron-Doped Single-Layer Graphene. ACS Nano 2012, 6, 6293-6300, doi:10.1021/nn301728j.

20. Sathe, B.R.; Zou, X.; Asefa, T. Metal-free B-doped graphene with efficient electrocatalytic activity for hydrogen evolution reaction. Catal. Sci. Technol. 2014, 4, 2023-2030, doi:10.1039/C4CY00075G.

21. Fang, H.; Yu, C.; Ma, T.; Qiu, J. Boron-doped graphene as a high-efficiency counter electrode for dye-sensitized solar cells. Chem. Commun. 2014, 50, 3328, doi:10.1039/c3ec48258h.

22. Peng, Z.; Ye, R.; Mann, J.A.; Zakhidov, D.; Li, Y.; Smalley, P.R.; Lin, J.; Tour, J.M. Flexible Boron-Doped Laser-Induced Graphene Microsupercapacitors. ACS Nano 2015, 9, 5868-5875, doi:10.1021/acsnano.5b00436. 
23. Yeom, D.-Y.; Jeon, W.; Tu, N.D.K.; Yeo, S.Y.; Lee, S.-S.; Sung, B.J.; Chang, H.; Lim, J.A.; Kim, H. High-concentration boron doping of graphene nanoplatelets by simple thermal annealing and their supercapacitive properties. Scientific Reports 2015, 5, 9817, doi:10.1038/srep09817.

24. Wang, L.; Sofer, Z.; Šimek, P.; Tomandl, I.; Pumera, M. Boron-Doped Graphene: Scalable and Tunable p-Type Carrier Concentration Doping. J. Phys. Chem. C 2013, 117, 2325123257, doi:10.1021/jp405169j.

25. Jo, G.; Sanetuntikul, J.; Shanmugam, S. Boron and phosphorous-doped graphene as a metal-free electrocatalyst for the oxygen reduction reaction in alkaline medium. RSC Adv. 2015, 5, 53637-53643, doi:10.1039/C5RA06952A.

26. Telychko, M.; Mutombo, P.; Merino, P.; Hapala, P.; Ondráček, M.; Bocquet, F.C.; Sforzini, J.; Stetsovych, O.; Vondráček, M.; Jelínek, P.; et al. Electronic and Chemical Properties of Donor, Acceptor Centers in Graphene. ACS Nano 2015, 9, 9180-9187, doi:10.1021/acsnano.5b03690.

27. Norimatsu, W.; Hirata, K.; Yamamoto, Y.; Arai, S.; Kusunoki, M. Epitaxial growth of boron-doped graphene by thermal decomposition of B4C. J. Phys.: Condens. Matter 2012, 24, 314207, doi:10.1088/0953-8984/24/31/314207.

28. Bleu, Y.; Bourquard, F.; Tite, T.; Loir, A.-S.; Maddi, C.; Donnet, C.; Garrelie, F. Review of Graphene Growth From a Solid Carbon Source by Pulsed Laser Deposition (PLD). Front Chem 2018, 6, doi:10.3389/fchem.2018.00572.

29. Bourquard, F.; Bleu, Y.; Loir, A.-S.; Caja-Munoz, B.; Avila, J.; Asensio, M.-C.; Raimondi, G.; Shokouhi, M.; Rassas, I.; Farre, C.; et al. Electroanalytical Performance of Nitrogen-Doped Graphene Films Processed in One Step by Pulsed Laser Deposition Directly Coupled with Thermal Annealing. Materials 2019, 12, 666, doi:10.3390/ma12040666.

30. Maddi, C.; Bourquard, F.; Barnier, V.; Avila, J.; Asensio, M.-C.; Tite, T.; Donnet, C.; Garrelie, F. Nano-Architecture of nitrogen-doped graphene films synthesized from a solid CN source. Scientific Reports 2018, 8, 3247, doi:10.1038/s41598-018-21639-9.

31. Bleu, Y.; Bourquard, F.; Barnier, V.; Lefkir, Y.; Reynaud, S.; Loir, A.-S.; Garrelie, F.; Donnet, C. Boron-doped graphene synthesis by pulsed laser co-deposition of carbon and boron. Applied Surface Science 2020, 513, 145843, doi:10.1016/j.apsusc.2020.145843.

32. Sikora, A.; Bourgeois, O.; Sanchez-Lopez, J.C.; Rouzaud, J.-N.; Rojas, T.C.; Loir, A.-S.; Garden, J.-L.; Garrelie, F.; Donnet, C. Effect of boron incorporation on the structure and electrical properties of diamond-like carbon films deposited by femtosecond and nanosecond pulsed laser ablation. Thin Solid Films 2009, 518, 1470-1474, doi:10.1016/j.tsf.2009.09.111.

33. Yao, Z.; Hu, M.; Iqbal, Z.; Wang, X. $\mathrm{N}_{8}{ }^{-}$Polynitrogen Stabilized on Boron-Doped Graphene as Metal-Free Electrocatalysts for Oxygen Reduction Reaction. ACS Catal. 2020, 10, 160-167, doi:10.1021/acscatal.9b03610.

34. Li, Y.; Wang, Z.; Lv, X.-J. N-doped TiO2 nanotubes/N-doped graphene nanosheets composites as high performance anode materials in lithium-ion battery. J. Mater. Chem. A 2014, 2, 15473-15479, doi:10.1039/C4TA02890B.

35. Wagner, C.D.; Davis, L.E.; Zeller, M.V.; Taylor, J.A.; Raymond, R.H.; Gale, L.H. Empirical atomic sensitivity factors for quantitative analysis by electron spectroscopy for chemical analysis. Surf. Interface Anal. 1981, 3, 211-225, doi:10.1002/sia.740030506.

36. Bleu, Y.; Barnier, V.; Christien, F.; Bourquard, F.; Loir, A.-S.; Garrelie, F.; Donnet, C. Dynamics of carbon diffusion and segregation through nickel catalyst, investigated by insitu XPS, during the growth of nitrogen-doped graphene. Carbon 2019, 155, 410-420, doi:10.1016/j.carbon.2019.08.084. 
37. Weatherup, R.S.; Baehtz, C.; Dlubak, B.; Bayer, B.C.; Kidambi, P.R.; Blume, R.; Schloegl, R.; Hofmann, S. Introducing Carbon Diffusion Barriers for Uniform, HighQuality Graphene Growth from Solid Sources. Nano Lett. 2013, 13, 4624-4631, doi:10.1021/nl401601x.

38. Banno, K.; Mizuno, M.; Fujita, K.; Kubo, T.; Miyoshi, M.; Egawa, T.; Soga, T. Transferfree graphene synthesis on insulating substrates via agglomeration phenomena of catalytic nickel films. Appl. Phys. Lett. 2013, 103, 082112, doi:10.1063/1.4818342.

39. Bleu, Y.; Bourquard, F.; Barnier, V.; Lefkir, Y.; Reynaud, S.; Loir, A.-S.; Garrelie, F.; Donnet, C. Boron-doped graphene synthesis by pulsed laser co-deposition of carbon and boron. Applied Surface Science 2020, 513, 145843, doi:10.1016/j.apsusc.2020.145843.

40. Bleu, Y.; Bourquard, F.; Gartiser, V.; Loir, A.-S.; Caja-Munoz, B.; Avila, J.; Barnier, V.; Garrelie, F.; Donnet, C. Graphene synthesis on $\mathrm{SiO} 2$ using pulsed laser deposition with bilayer predominance. Materials Chemistry and Physics 2019, 238, 121905, doi:10.1016/j.matchemphys.2019.121905.

41. Miyoshi, M.; Mizuno, M.; Banno, K.; Kubo, T.; Egawa, T.; Soga, T. Study on transferfree graphene synthesis process utilizing spontaneous agglomeration of catalytic $\mathrm{Ni}$ and Co metals. Mater. Res. Express 2015, 2, 015602, doi:10.1088/2053-1591/2/1/015602.

42. Cheng, W.; Liu, X.; Li, N.; Han, J.; Li, S.; Yu, S. Boron-doped graphene as a metal-free catalyst for gas-phase oxidation of benzyl alcohol to benzaldehyde. RSC Advances $\mathbf{2 0 1 8}$, 8, 11222-11229, doi:10.1039/C8RA00290H.

43. Chowdhury, S.; Jiang, Y.; Muthukaruppan, S.; Balasubramanian, R. Effect of boron doping level on the photocatalytic activity of graphene aerogels. Carbon 2018, 128, 237248, doi:10.1016/j.carbon.2017.11.089.

44. Sun, Y.; Du, C.; An, M.; Du, L.; Tan, Q.; Liu, C.; Gao, Y.; Yin, G. Boron-doped graphene as promising support for platinum catalyst with superior activity towards the methanol electrooxidation reaction. Journal of Power Sources 2015, 300, 245-253, doi:10.1016/j.jpowsour.2015.09.046.

45. Xu, X.; Yuan, T.; Zhou, Y.; Li, Y.; Lu, J.; Tian, X.; Wang, D.; Wang, J. Facile synthesis of boron and nitrogen-doped graphene as efficient electrocatalyst for the oxygen reduction reaction in alkaline media. International Journal of Hydrogen Energy 2014, 39, 1604316052, doi:10.1016/j.ijhydene.2013.12.079.

46. Yu, X.; Han, P.; Wei, Z.; Huang, L.; Gu, Z.; Peng, S.; Ma, J.; Zheng, G. Boron-Doped Graphene for Electrocatalytic N2 Reduction. Joule 2018, 2, 1610-1622, doi:10.1016/j.joule.2018.06.007.

47. Sahoo, M.; Sreena, K.P.; Vinayan, B.P.; Ramaprabhu, S. Green synthesis of boron doped graphene and its application as high performance anode material in $\mathrm{Li}$ ion battery. Materials Research Bulletin 2015, 61, 383-390, doi:10.1016/j.materresbull.2014.10.049.

48. Malard, L.M.; Pimenta, M.A.; Dresselhaus, G.; Dresselhaus, M.S. Raman spectroscopy in graphene. Physics Reports 2009, 473, 51-87, doi:10.1016/j.physrep.2009.02.003.

49. Ferrari, A.C.; Meyer, J.C.; Scardaci, V.; Casiraghi, C.; Lazzeri, M.; Mauri, F.; Piscanec, S.; Jiang, D.; Novoselov, K.S.; Roth, S.; et al. Raman Spectrum of Graphene and Graphene Layers. Phys. Rev. Lett. 2006, 97, 187401, doi:10.1103/PhysRevLett.97.187401.

50. Graf, D.; Molitor, F.; Ensslin, K.; Stampfer, C.; Jungen, A.; Hierold, C.; Wirtz, L. Raman mapping of a single-layer to double-layer graphene transition. Eur. Phys. J. Spec. Top. 2007, 148, 171-176, doi:10.1140/epjst/e2007-00237-1.

51. Peng, Z.; Yan, Z.; Sun, Z.; Tour, J.M. Direct Growth of Bilayer Graphene on SiO2 Substrates by Carbon Diffusion through Nickel. ACS Nano 2011, 5, 8241-8247, doi:10.1021/nn202923y. 
52. Xiong, W.; Zhou, Y.S.; Jiang, L.J.; Sarkar, A.; Mahjouri-Samani, M.; Xie, Z.Q.; Gao, Y.; Ianno, N.J.; Jiang, L.; Lu, Y.F. Single-Step Formation of Graphene on Dielectric Surfaces. Advanced Materials 2013, 25, 630-634, doi:10.1002/adma.201202840.

53. Gong, Y.; Zhang, X.; Liu, G.; Wu, L.; Geng, X.; Long, M.; Cao, X.; Guo, Y.; Li, W.; Xu, $\mathrm{J}$; ; et al. Layer-Controlled and Wafer-Scale Synthesis of Uniform and High-Quality Graphene Films on a Polycrystalline Nickel Catalyst. Advanced Functional Materials 2012, 22, 3153-3159, doi:10.1002/adfm.201200388.

54. Cançado, L.G.; Takai, K.; Enoki, T.; Endo, M.; Kim, Y.A.; Mizusaki, H.; Jorio, A.; Coelho, L.N.; Magalhães-Paniago, R.; Pimenta, M.A. General equation for the determination of the crystallite size La of nanographite by Raman spectroscopy. Appl. Phys. Lett. 2006, 88, 163106, doi:10.1063/1.2196057.

55. Lin, T.; Huang, F.; Liang, J.; Wang, Y. A facile preparation route for boron-doped graphene, and its CdTe solar cell application. Energy Environ. Sci. 2011, 4, 862-865, doi:10.1039/C0EE00512F.

56. Ferrari, A.C.; Robertson, J. Interpretation of Raman spectra of disordered amorphous carbon. Physical Review B 2000, 61, 14095-14107.

57. Tongay, S.; Berke, K.; Lemaitre, M.; Nasrollahi, Z.; Tanner, D.B.; Hebard, A.F.; Appleton, B.R. Stable hole doping of graphene for low electrical resistance and high optical transparency. Nanotechnology 2011, 22, 425701, doi:10.1088/09574484/22/42/425701.

58. Lee, D.S.; Riedl, C.; Krauss, B.; von Klitzing, K.; Starke, U.; Smet, J.H. Raman Spectra of Epitaxial Graphene on SiC and of Epitaxial Graphene Transferred to SiO2. Nano Lett. 2008, 8, 4320-4325, doi:10.1021/nl802156w.

59. Röhrl, J.; Hundhausen, M.; Emtsev, K.V.; Seyller, Th.; Graupner, R.; Ley, L. Raman spectra of epitaxial graphene on SiC(0001). Appl. Phys. Lett. 2008, 92, 201918, doi:10.1063/1.2929746.

60. Ni, Z.H.; Wang, H.M.; Ma, Y.; Kasim, J.; Wu, Y.H.; Shen, Z.X. Tunable Stress and Controlled Thickness Modification in Graphene by Annealing. ACS Nano 2008, 2, 10331039, doi:10.1021/nn800031m.

61. Lavagnini, I.; Antiochia, R.; Magno, F. An Extended Method for the Practical Evaluation of the Standard Rate Constant from Cyclic Voltammetric Data. Electroanalysis 2004, 16, 505-506, doi:10.1002/elan.200302851.

62. Niu, L.; Li, Z.; Hong, W.; Sun, J.; Wang, Z.; Ma, L.; Wang, J.; Yang, S. Pyrolytic synthesis of boron-doped graphene and its application as electrode material for supercapacitors. Electrochimica Acta 2013, 108, 666-673, doi:10.1016/j.electacta.2013.07.025.

63. Brownson, D.A.C.; Kampouris, D.K.; Banks, C.E. Graphene electrochemistry: fundamental concepts through to prominent applications. Chem. Soc. Rev. 2012, 41, 6944, doi: $10.1039 / \mathrm{c} 2 \mathrm{cs} 35105 \mathrm{f}$.

64. Liu, X.; Sartin, M.M.; Liu, Y.; Tian, Z.-Q.; Zhan, D. Optimizing the interfacial electron transfer capability of single layer graphene by thermal annealing. Chem. Commun. 2020, 56, 253-256, doi:10.1039/C9CC08150J. 